LIVER

\title{
Toll-like receptors 2 and 4 are differentially involved in Fas dependent apoptosis in Peyer's patch and the liver at an early stage after bile duct ligation in mice
}

\author{
A Ogawa, T Tagawa, H Nishimura, T Yajima, T Abe, T Arai, M Taniguchi, K Takeda, \\ S Akira, Y Nimura, Y Yoshikai
}

See end of article for authors' affiliations

Correspondence to:

Correspondence to:
Dr Y Yoshikai, Division of Host Defense, Medical Institute of Bioregulation, Kyushu University, 3-1-1 Maidashi, Higashi-ku, Fukuoka 812-8582, Japan; yoshikai@ bioreg.kyushu-u.ac.jp

Revised version received 6 July 2005 Accepted for publication 24 July 2005 Published online first 23 August 2005
Background and aims: Surgical management of extrahepatic cholestasis is frequently complicated by bacterial translocation and severe liver injury. The aim of this study was to clarify the involvement of Tolllike receptors (TLRs) in the pathogenesis of bacterial translocation and liver injury in obstructive cholestasis. Methods: TLR2 deficient (TLR2 ${ }^{-1-}$ ), MyD88 ${ }^{-/-}, \mathrm{J} \alpha 281^{-/-}$, gld/gld, and lpr/lpr mice, all of which have a $\mathrm{C} 57 \mathrm{BL} / 6$ background, and $\mathrm{C} 3 \mathrm{H} / \mathrm{HeN}$ and TLR4 mutated $\mathrm{C} 3 \mathrm{H} / \mathrm{HeJ}$ mice were subjected to bile duct ligation (BDL). Faecal $\lg \mathrm{A}$ and serum alanine aminotransferase levels were determined after BDL. Apoptosis was examined by histological and flow cytometric analyses of cells from Peyer's patches and the liver

Results: The size and number of B cells in Peyer's patches markedly decreased on day 3 after BDL. Increased apoptosis in Peyer's patch B cells was evident on day 1 after BDL in control mice but not in lpr/ Ipr, $\mathrm{MyD} 8^{-/-}$, or $\mathrm{C} 3 \mathrm{H} / \mathrm{HeJ}$ mice. On the other hand, TLR2 and Fas ligand expression on intrahepatic $\mathrm{NK} 1.1^{+} \mathrm{T}$ cells increased on day 1 after BDL in C57BL/6 mice. Liver injury and apoptosis were evident on day 1 after $\mathrm{BDL}$ in control and $\mathrm{C} 3 \mathrm{H} / \mathrm{HeJ}$ mice but were significantly reduced in TLR2 ${ }^{-/-}, \mathrm{J} \alpha 281^{-/-}$, gld/ gld, and lpr/lpr mice.

Conclusions: TLR4 and TLR2 may play important roles in Fas dependent apoptosis in Peyer's patch B cells and hepatocytes, respectively, at an early stage after BDL in mice.
$\mathrm{T}$ oll was first identified as a protein controlling dorsoventral pattern formation in the early stages of development of Drosophila ${ }^{1}$ and was shown to participate in antimicrobial immune responses. ${ }^{2}$ Mammalian Toll homologues, Toll-like receptors (TLR) have been identified ${ }^{3}$ and shown to play important roles in pattern recognition of various bacterial components. ${ }^{4-13}$ TLR signalling leads to activation of innate immunity, which prompts local host defence against microbial infection. However, excessive and uncontrollable activation of innate immunity often causes tissue injury in organs and systemic reactions leading to lethal shock..$^{14}$ We have recently reported that TLR2 and TLR4 contribute not only to protection but also to the pathogenesis of liver injury caused by Gram negative bacterial infection. ${ }^{16-18}$ Thus TLR signalling is involved in not only protection but also in tissue injury during microbial infection.

Surgical management of extrahepatic cholestasis is frequently complicated by sepsis which can be explained in part by diminished functions of the host defence mechanisms. ${ }^{19-21}$ Bacterial translocation from the gut is thought to be another major mechanism accounting for septic complications in patients with obstructive jaundice. ${ }^{22}{ }^{23}$ It has been suggested that lowered secretion of bile into the intestine causes loss of mucosal integrity, which promotes bacterial translocation from the gut. ${ }^{24}{ }^{25}$ Impaired ability of phagocytes to accumulate in the inflamed site and to phagocytise and kill the bacteria under cholestatic conditions have been reported. ${ }^{26-28}$ Thus dysfunction of mucosal immunity may be responsible for bacterial translocation from the gut. Cholestasis also causes hepatocellular injury by inducing apoptosis in hepatocytes. Retention and accumulation of toxic hydrophobic bile salts within hepatocytes are mainly responsible for liver injury. ${ }^{29-34}$ It has recently been reported that hepatocyte apoptosis after bile duct ligation (BDL) is mediated by a Fas dependent pathway. ${ }^{35-37}$ Therefore, it can be speculated that uncontrollable activation of innate immunity may at least partly contribute to liver injury in obstructive cholestasis.

The aim of this study was to clarify the involvement of TLRs in the pathogenesis of bacterial translocation and liver injury in obstructive cholestasis. Our results suggest that TLR4 and TLR2 play important roles in induction of apoptosis in Peyer's patch B cells and hepatocytes, respectively, at an early stage after BDL in mice.

\section{MATERIALS AND METHODS \\ Mice}

Seven to eight week old female C57BL/6, gld/gld, and $l p r / l p r$ mice with a $\mathrm{B} 6$ background, $\mathrm{C} 3 \mathrm{H} / \mathrm{HeN}$, and $\mathrm{C} 3 \mathrm{H} / \mathrm{HeJ}$ mice were purchased from Japan SLC, Inc. (Hamamatsu, Japan). Mutant mice deficient in TLR2, MyD88, or J 2281 with a C57BL/6 background were generated by gene targeting, as described previously. ${ }^{5}{ }^{638}$ Age and sex matched groups of homozygous mice and their littermate $\left(\mathrm{TLR} 2^{+/}\right.$) mice were used for the experiments. In some experiments, siblings from the same mother were used. All of the mice used for the

Abbreviations: ALT, alanine aminotransferase; BDL, bile duct ligation/ bile duct ligated; CLP, caecal ligation and puncture; FasL, Fas ligand; FITC, fluorescein isothiocyanate; GAPDH, glyceraldehyde-3-phosphate dehydrogenase; GCDC, glycoenodeoxylase; HBSS, Hank's balanced salt solution; mAb, monoclonal antibody; PBS, phosphate buffered saline; PCR, polymerase chain reaction; PE, phycoerythrin; PI, propidium iodide; TLR, Toll-like receptor; TUNEL, terminal deoxynucleotidyl transferase dUTP nick end labelling 
experiments were maintained under specific pathogen free conditions in our animal facility.

\section{Surgical procedure}

After seven days of acclimatisation, surgery was performed under sterile conditions. Mice were anaesthetised by intraperitoneal pentobarbital injection $(50 \mathrm{mg} / \mathrm{kg})$. An abdominal midline incision was made, and the common bile duct was identified, ligated, and divided as previously described. ${ }^{26}$ Control animals underwent a sham procedure in which the common bile duct was identified and exposed but not ligated.

\section{Preparation of cells}

Fresh liver was immediately perfused with sterile Hank's balanced salt solution (HBSS) through the portal vein to wash out all remaining peripheral blood and then meshed with stainless steel mesh. After coarse pieces had been removed by centrifugation at $50 \mathrm{~g}$ for one minute, cell suspensions were again centrifuged, resuspended in $8 \mathrm{ml}$ of 45\% Percoll (Amersham Biosciences, Uppsala, Sweden), and layered on $5 \mathrm{ml}$ of $66.6 \%$ Percoll. The gradients were centrifuged at $600 \mathrm{~g}$ for 20 minutes at $20^{\circ} \mathrm{C}$. Lymphocytes at the interface were harvested and washed twice with HBSS. Peyer's patches (4-6 patches per mouse) were excised aseptically from the exposed small intestine.

\section{Bacterial growth in organs}

Peritoneal exudates were obtained from the peritoneal cavity by lavage with $3 \mathrm{ml}$ of HBSS. For enumeration of viable bacteria in the liver, the liver was perfused with $8 \mathrm{ml}$ of sterile HBSS to wash out bacteria in the blood vessels immediately after mice had been bled. The liver and spleen were removed and separated into sterile Teflon coated homogenisers (Asahi Techno Glass Co., Tokyo, Japan), each containing $2 \mathrm{ml}$ of cold phosphate buffered saline (PBS). After each organ had been homogenised thoroughly, bacterial counts in homogenates were established by plating serial 10 -fold dilutions in sterile distilled water on blood agar and MacConkey agar (Nissui, Tokyo, Japan). Colonies were counted 24 hours later, after incubation at $37^{\circ} \mathrm{C}$.

\section{Flow cytometric analysis}

Cells were preincubated with a culture supernatant from 2.4G2 (anti-FcRII/III-specific) monoclonal antibody (mAb) (rat-IgG $G_{1}$ producing hybridoma) to prevent non-specific staining. For identification of lymphocytes, cells were stained with fluorescein isothiocyanate (FITC) conjugated anti-CD3 $\mathrm{mAb}$, phycoerythrin (PE) conjugated B220 mAb, and biotinylated anti-NK1.1 mAb (PharMingen,San Diego, California, USA). To detect biotin conjugated mAb, cells were stained with $\mathrm{Cy}$-Chrome conjugated streptavidin. All incubation steps were performed at $4^{\circ} \mathrm{C}$ for 30 minutes. For the annexin $\mathrm{V}$ staining assay, cells were stained with antiB220 mAb coupled to PE and biotinylated anti-mAb. Cells were then washed with HBSS and were incubated with $5 \mu \mathrm{l}$ of FITC conjugated annexin V for 15 minutes at room temperature in the dark, after which $400 \mu \mathrm{l}$ of $1 \times$ binding buffer were added, as recommended by the manufacturer. For propidium iodide (PI) staining, cells were washed twice with PBS and fixed with ice cold $70 \%$ ethanol/PBS. Cells were then kept on ice for at least one hour. Subsequently, the medium was removed by centrifugation, and pellets were resuspended in $100 \mu \mathrm{l}$ PBS. Cells were then incubated in the dark for 30 minutes at $4^{\circ} \mathrm{C}$ in the presence of PI $(50 \mu \mathrm{g} / \mathrm{ml}$; Sigma, St Louis, Missouri, USA) and DNase-free RNase A $(250 \mu \mathrm{g} / \mathrm{ml}$; Roche, Indianapolis, Indiana, USA). Thereafter, cell cycle status and apoptosis were determined using a FACSCalibur flow cytometer (Becton Dickinson \& Co., San Jose, California, USA).

\section{IgA in faecal samples}

Faecal samples $(0.02 \mathrm{~g})$ was each incubated with $1 \mathrm{ml}$ of PBS at room temperature for 60 minutes, vortexed, left for 15 minutes, revortexed until all materials were suspended, and centrifuged at $2000 \mathrm{~g}$ for 10 minutes. The supernatants were removed and tested for total IgA by enzyme linked immunosorbent assay.

\section{Histopathological examination}

The liver and Peyer's patches were removed and fixed in 10\% buffered formalin. After paraffin embedding, tissue sections were cut $(3 \mu \mathrm{m})$ and stained with haematoxylin-eosin for morphological evaluation. An experienced hepatopathologist evaluated the sections and graded them as follows: grade 0 , normal histomorphology; grade 1 , minor inflammatory infiltrates with occasional liver cell necrosis; grade 2, moderate liver damage with inflammatory infiltrates and focal necroses; and grade 3, extensive liver damage accompanied by diffusely distributed cell necroses. At least three separate sections were assessed per liver in each group of five mice in a blinded fashion. In situ terminal deoxynucleotidyl transferase dUTP nick end labelling (TUNEL) assay was performed using an in situ apoptosis detection kit (Apoptag, Intergen, Purchase, New York, USA). All steps were performed according to the manufacturer's instructions. Briefly, paraffin embedded sections were deparaffinised and rehydrated and then permeabilised by incubation with 0.55 unit/ml proteinase K (Wako, Tokyo, Japan) for 15 minutes at $37^{\circ} \mathrm{C}$. Tissue sections were then washed in distilled water. Inactivation of endogenous peroxidases was accomplished by immersing the tissue sections in 3\% hydrogen peroxide diluted in methanol for 10 minutes at room

\begin{tabular}{|c|c|c|c|c|c|c|}
\hline & $\begin{array}{l}\text { Days after } \\
\text { operation }\end{array}$ & Liver & $\begin{array}{l}\text { Mesenteric } \\
\text { lymph nodes }\end{array}$ & Spleen & $\begin{array}{l}\text { Peritoneal } \\
\text { exudate }\end{array}$ & Bile \\
\hline \multirow[t]{4}{*}{ Sham } & 1 & $0 / 6$ & $0 / 6$ & $0 / 6$ & $0 / 6$ & $0 / 6$ \\
\hline & 3 & $0 / 6$ & $0 / 6$ & $0 / 6$ & $0 / 6$ & $0 / 6$ \\
\hline & 5 & $0 / 6$ & $0 / 6$ & $0 / 6$ & $0 / 6$ & $0 / 6$ \\
\hline & 7 & $0 / 6$ & $0 / 6$ & $0 / 6$ & $0 / 6$ & $0 / 6$ \\
\hline \multirow[t]{4}{*}{ BDL } & 1 & $0 / 6$ & $0 / 6$ & $0 / 6$ & $0 / 6$ & $0 / 6$ \\
\hline & 3 & $1 / 6$ & $1 / 6$ & $0 / 6$ & $0 / 6$ & $0 / 6$ \\
\hline & 5 & $2 / 6$ & $3 / 6^{*}$ & $0 / 6$ & $0 / 6$ & $0 / 6$ \\
\hline & 7 & $2 / 6$ & $3 / 6^{*}$ & $0 / 6$ & $0 / 6$ & $0 / 6$ \\
\hline \multicolumn{7}{|c|}{$\begin{array}{l}\text { Values represent the incidence of bacterial translocation in the liver, mesenteric lymph nodes, spleen, peritonec } \\
\text { exudates, and bile of } B D L \text { and sham operated mice }(n=6) \text { on the indicated days after operation. } \\
{ }^{*} \mathrm{p}<0.05 \text {. }\end{array}$} \\
\hline
\end{tabular}




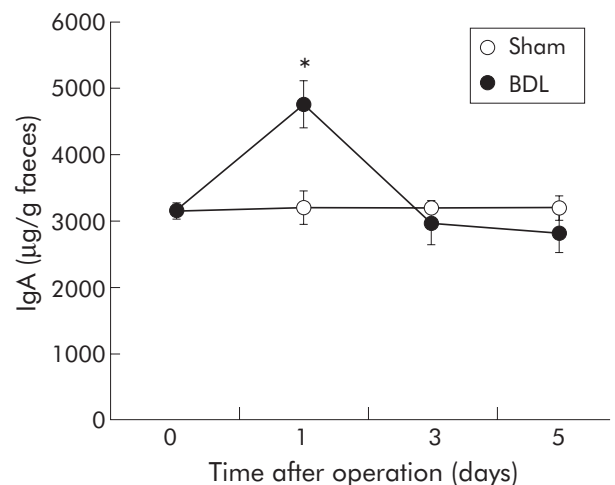

Figure 1 Kinetics of faecal $\lg \mathrm{A}$ levels after bile duct ligation (BDL). Faecal samples $(0.02 \mathrm{~g})$ were each incubated with $1 \mathrm{ml}$ of phosphate buffered saline at room temperature for 60 minutes, vortexed, left for 15 minutes, revortexed until all materials were suspended, and centrifuged at $2000 \mathrm{~g}$ for 10 minutes. The supernatants were removed and tested for total IgA by enzyme linked immunosorbent assay. ${ }^{*} \mathrm{p}<0.01$ compared with sham operated mice.

temperature. After the slides had been washed with distilled water, sections were incubated in equilibration buffer for five minutes. Sections were then incubated with a labelling solution containing terminal deoxynucleotidyl transferase in a humidified chamber for one hour at $37^{\circ} \mathrm{C}$. Reactions were terminated by rinsing the sections in a stop/wash buffer. The incorporated digitonigen-dUTP was detected by incubation with antidigoxigenin peroxidase at room temperature for 30 minutes, and positive reactions were revealed using 3,3' diaminobenzidine. Haematoxylin was used for counterstaining nuclei, and slides were coverslipped.

\section{Real time polymerase chain reaction (PCR)}

mRNA was obtained from EPICS sorted NK, NKT, or T cells in the liver using the Quick Prep Micro mRNA Purification kit (Amersham Biosciences, Buckinghamshire, UK). Each RNA sample was reverse transcribed into cDNA using random primers and Moloney murine leukaemia virus transcriptase. Real time PCR was performed using a Taq Man PCR kit (Applied Biosystems, Foster City, California, USA) and primers for Fas ligand (FasL). Glyceraldehyde-3-phosphate dehydrogenase (GAPDH) primers were used as a control for RNA isolation and integrity. Real time PCR was performed using the ABI PRISM 7000 sequence detector thermal cycler (Applied Biosystem). Results were expressed as a ratio of product copies $/ \mathrm{ml}$ to copies $/ \mathrm{ml}$ of the housekeeeping gene GAPDH from the same RNA (respective cDNA) sample and PCR run.

\section{Assay for serum alanine aminotransaminase (ALT) and caspase 3 activity in liver tissues}

Serum ALT activity was determined using a transaminase test kit (Wako, Osaka, Japan). Serum total bilirubin levels were measured using a commercially available kit following the manufacturer's instructions (Sigma Diagnostics Kit No550 for bilirubin; Sigma Chemical Co). The activity of caspase 3 was determined by the Fluorometric CaspACE Assay System (Promega, Madison, Wisconsin, USA) according to the manufacturer's instructions. Briefly, fresh isolated liver was meshed with a stainless steal mesh and resuspended in hypotonic lysis buffer. Cells were lysed by subjecting them to four cycles of freezing and thawing. After centrifuging, the activity of caspase 3 in the supernatant was measured with fluorogenic caspase 3 substrate (Ac-DEVD-AMC) at an excitation wavelength of $360 \mathrm{~nm}$ and an emission wavelength of $460 \mathrm{~nm}$.

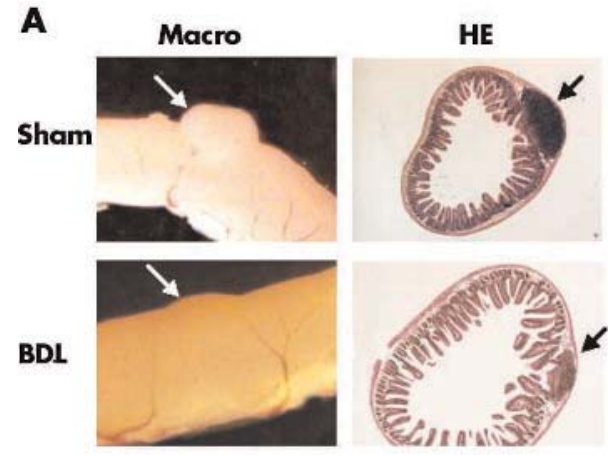

B

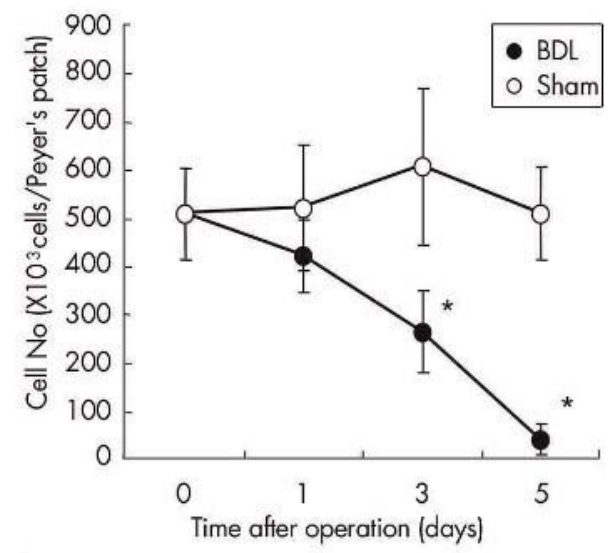

C

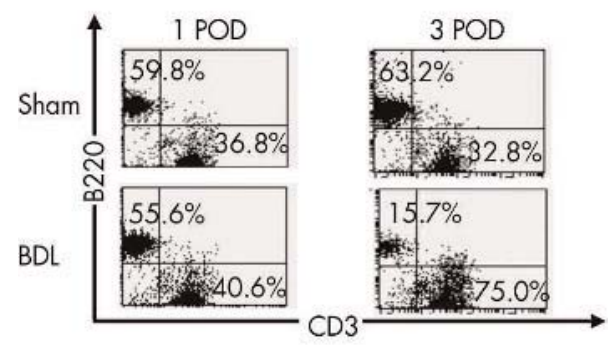

Figure 2 Comparison of sizes and degrees of cellularity of Peyer's patches from bile duct ligated (BDL) and sham operated mice. (A) Sizes of Peyer's patches after BDL. Peyer's patches in C57BL/6 mice were obtained on day 3 after BDL. Formalin fixed paraffin embedded thin specimens were stained with haematoxylin-eosin (HE), and microscopic analyses were performed. Arrow indicates a Peyer's patch. (B) Numbers of total cells in Peyer's patches after BDL. ${ }^{*} p<0.05$ compared with sham operated mice. (C) Flow cytometric analysis on lymphocytes of Peyer's patches in BDL mice. Peyer's patches in C57BL/ 6 mice were obtained on day 3 after BDL, stained with anti-B220 and anti-CD3 monoclonal antibody, and analysed with FACSCalibur. Analysis gate was set on lymphocytes using forward and side scatter.

\section{Statistical analysis}

Data were analysed by the Student's $t$ test and Fisher's exact test, and a Bonferroni correction was applied for multiple comparison. The value of $\mathrm{p}<0.05$ was considered statistically significant.

\section{RESULTS}

\section{Bacterial translocation after BDL}

It has been reported that cholestasis promoted bacterial translocation from the gut. ${ }^{22}{ }^{23}$ To determine whether bacterial translocation occurs in cholestatic mice, we examined the translocation of Enterobacteriae in the liver, 
A

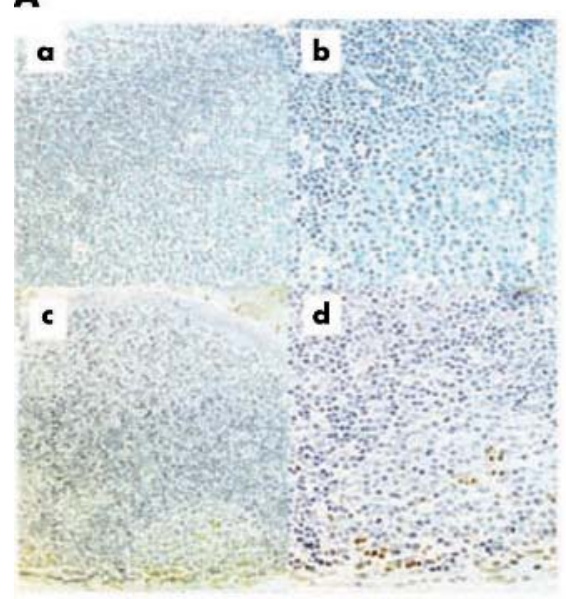

B

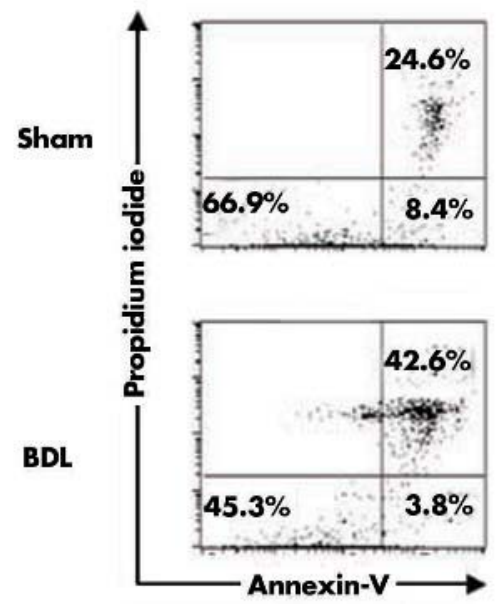

Figure 3 Apoptosis in Peyer's patch lymphocytes after bile duct ligation (BDL). (A) Apoptotic cells in situ in Peyer's patches after sham operation (a, b) or BDL (c, d). Peyer's patches in C57BL/6 mice were obtained on day 1 after BDL. Detection of DNA fragmentation was performed using the in situ terminal deoxynucleotidyl transferase dUTP nick end labelling (TUNEL) method, as described in the materials and methods. TUNEL positive cells are dark brown. Data shown are representative of three independent experiments. (Original magnification (left panel) $\times 100$; (right panel) $\times 400$.) (B) Flow cytometric analysis of Peyer's patch cells stained with annexin V. Peyer's patch cells obtained from BDL mice on day 1 after operation were stained with anti-B220 monoclonal antibody (mAb) and anti-annexin V mAb. Analysis gates were set on B220 corresponding to B cells. The percentage of annexin $\checkmark$ positive cells are indicated. Data shown are representative of three independent experiments.

mesenteric lymph nodes, spleen, peritoneal exudate, and bile in mice that had undergone BDL. Bacterial translocation was found three days after BDL in the liver and mesenteric lymph nodes whereas no bacteria were detected in sham operated mice $(\mathrm{p}<0.05)($ table 1$)$. Most of the bacteria were Escherichia coli and Entrococcus faecalis and a few were Klebisiella pneumonia and Staphylococcus aureus, all of which are present in bacterial flora. These results suggest that bacterial translocation from the intestine often occurs in BDL mice.

\section{Increased faecal IgA and apoptosis in Peyer's patch B lymphocytes after BDL}

IgA production is associated with bacterial translocation in BDL mice. ${ }^{39}$ We first examined IgA levels in the intestine after BDL. As shown in fig 1 , levels of IgA in faeces transiently increased on day 1 after BDL $(\mathrm{p}<0.01)$ and then decreased to control levels.

We next examined the size and cellularity of Peyer's patches after BDL. The sizes of Peyer's patches on day 1 after

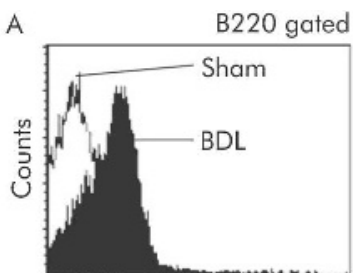

Fas

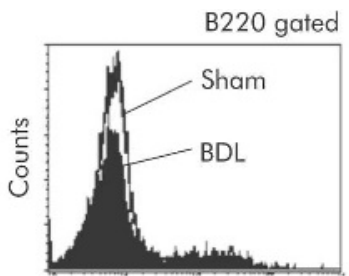

CD40

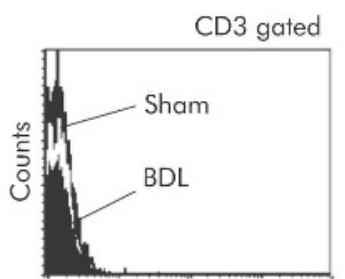

Fas L
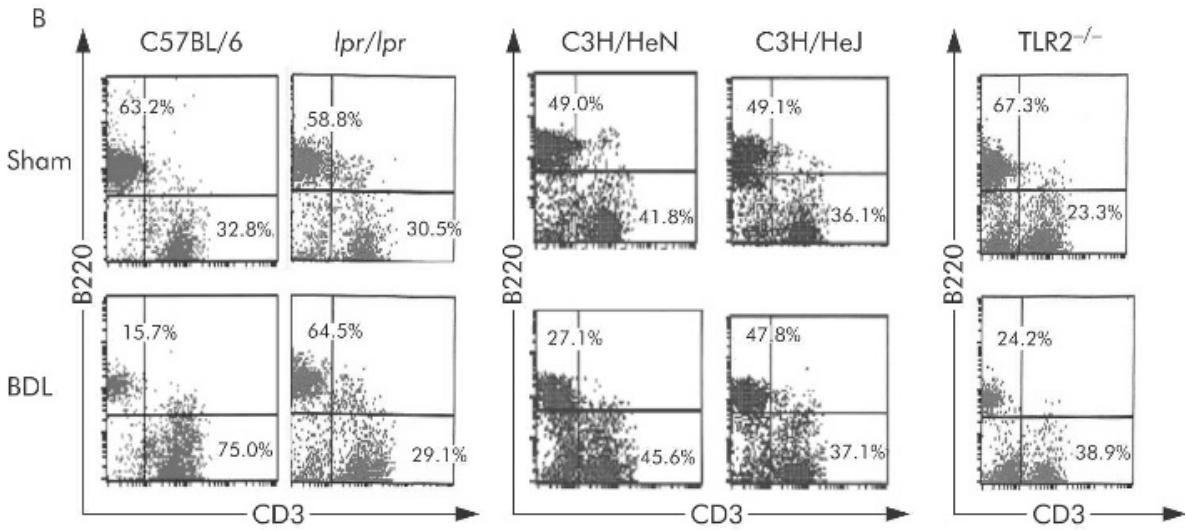

Figure 4 Flow cytometric analysis of Peyer's patch cells in $/ p r / l p r, \mathrm{TLR}^{-1-}$ and $\mathrm{C} 3 \mathrm{H} / \mathrm{HeJ}$ mice after bile duct ligation (BDL). (A) Expression of Fas, CD 40, and Fas ligand (FasL) on Peyer's patch cells after BDL. Peyer's patches in C57BL/6 mice were obtained on day 1 after BDL and stained with anti-B220 and anti-CD3 monoclonal antibody (mAb) and anti-Fas, FasL, or CD40 $\mathrm{mAb}$. The shaded area shows the BDL groups and unshaded area the sham operated groups. Data shown are representative of three independent experiments. (B) Flow cytometric analysis of lymphocytes of Peyer's patches in $/ p r / l p r, C 3 \mathrm{H} / \mathrm{HeN}, \mathrm{C} 3 \mathrm{H} /$ $\mathrm{HeJ}$, and TLR2 ${ }^{-1}$ mice after BDL. Peyer's patch cells were obtained on day 3 after operation and stained with anti-B220 and anti-CD3 mAb. Analysis gate was set on lymphocytes using forward and side scatter. The percentage of each fraction in total ymphocytes is indicated. 

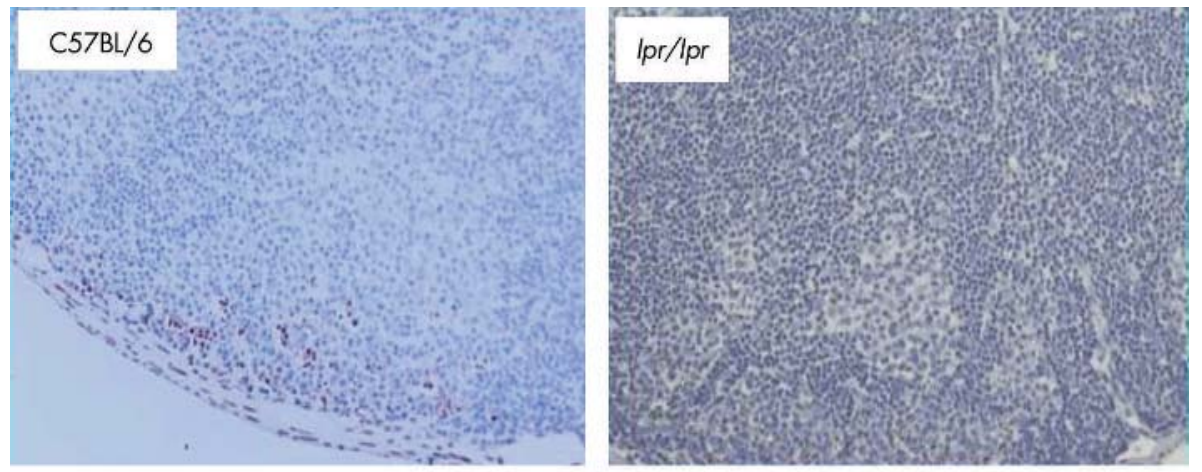

Figure 5 Apoptosis of Peyer's patch B cells after bile duct ligation (BDL) in lpr/ lpr, MyD88 $8^{-/-}$, and TLR4 $4^{-/-}$mice. Peyer's patches were obtained on day 1 after BDL. Detection of DNA fragmentation was performed using the in situ terminal deoxynucleotidyl transferase dUTP nick end labelling (TUNEL) method, as described in materials and methods. TUNEL positive cells are dark brown. Data shown are representative of three independent experiments.
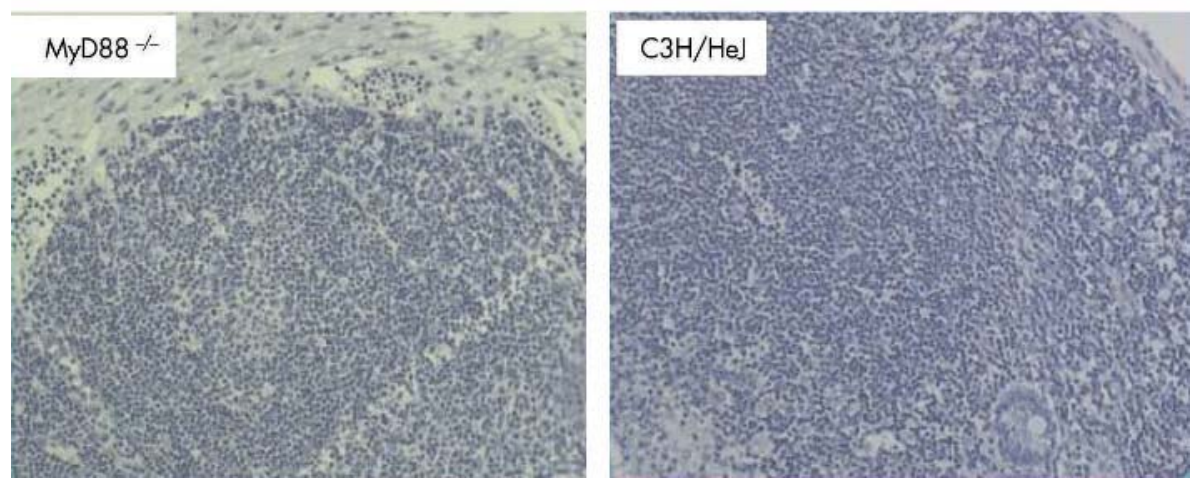

BDL were similar to those in sham operated mice (data not shown) but were markedly reduced on day 3 after BDL (fig 2A). Total cell numbers of Peyer's patches were significantly decreased by day 3 after BDL and thereafter $(\mathrm{p}<0.05)$ (fig 2B). Flow cytometric analysis revealed that the number of $\mathrm{B}^{2} 20^{+} \mathrm{B}$ cells decreased on day 3 after BDL (fig $2 \mathrm{C}$ ). We next attempted to assess the extent of apoptosis in Peyer's patches by the TUNEL technique. As shown in fig 3A, a large number of TUNEL positive cells were observed on day 1 after BDL. Cells showed characteristics of apoptosis, such as shrinking, chromatin clumping, and nuclear fragmentation, and they were mostly located in the germinal centres but not in the marginal zone, which is abundant in $\mathrm{T}$ cells. There were a few apoptotic cells in other organs such as the spleen on day 1 after BDL (data not shown). To determine the population of Peyer's patch cells undergoing apoptosis, we stained cells with anti-B220, anti-CD3 $\epsilon$, and anti-annexin V mAbs. Analysis gates were set on $\mathrm{B} 220^{+}$cells corresponding to $\mathrm{B}$ cells. A major increase in annexin $\mathrm{V}$ positive cells was observed on day 1 after BDL in Peyer's patch $\mathrm{B}$ cells (fig $3 \mathrm{~B}$ ) but not in T cells (data not shown). Thus increased apoptosis in Peyer's patches of BDL mice is restricted to cells of the $\mathrm{B}$ lineage.

\section{Involvement of Fas and TLR4 in apoptosis of Peyer's patch B cells after BDL}

The Fas/FasL system is known to be involved in B cell apoptosis. ${ }^{40-42}$ We therefore examined expression levels of Fas on Peyer's patch B cells after BDL. As shown in fig 4A, expression levels of Fas were significantly higher in B cells of Peyer's patches on day l after BDL than those of sham operated control mice. We found no difference in expression levels of CD40 on Peyer's patch B cells and FasL on Peyer's patch T cells on day 1 after BDL compared with those of sham operated mice.

To determine whether Fas signalling is involved in Peyer's patch B cell apoptosis in BDL mice, we examined apoptosis of B cells in Peyer's patches from lpr/lpr mice after BDL. The number of Peyer's patch B cells in lpr/lpr mice was not reduced after BDL, and apoptosis was not evident in $l p r / l p r$ mice after BDL (fig 4B, fig 5). Thus Fas signalling is important for apoptosis of B cells in Peyer's patches after BDL. We next examined whether TLR signalling is involved in B cell apoptosis after BDL using TLR4 mutated C3H/HeJ mice or mice deficient in TLR2 or MyD88, a key adaptor protein for most of the TLRs. ${ }^{4}$ As shown in fig 4B, the number of Peyer's patch $\mathrm{B}$ cells was reduced in $\mathrm{C} 3 \mathrm{H} / \mathrm{NeN}$ and $\mathrm{TLR}^{-/-}$mice but not in $\mathrm{C} 3 \mathrm{H} / \mathrm{HeJ}$ mice. Apoptosis in Peyer's patch was not evident in $\mathrm{C} 3 \mathrm{H} / \mathrm{NeJ}$ or $\mathrm{MyD} 88^{-/-}$mice after BDL (fig 5). These results suggest that MyD88 dependent TLR4 signalling plays an important role in Peyer's patch B cell apoptosis after BDL.

\section{Increased expression of FasL and TLR2 on intrahepatic NKT cells after BDL}

We previously reported that FasL expression was selectively induced on NK T cells via TLR2 signalling and it was partly responsible for liver injury caused by Gram negative bacterial infection. ${ }^{17}{ }^{18}$ To determine whether expression of FasL and TLR2 was induced on NK T cells in vivo by BDL, we analysed expression of FasL and TLR2 on intrahepatic lymphocytes of C57BL/6 mice on day 1 after BDL by flow cytometry. No change in the number of NK and NK T cells was observed between before and after BDL in C57BL/6 mice (data not shown). As shown in fig 6A, expression levels of FasL and TLR2 on NK T cells were apparently increased after BDL. Although NK cells expressed slightly increased levels of FasL and TLR2 after BDL, T cells did not express these even after BDL. We further examined FasL mRNA expression by real time PCR and found that FasL mRNA was increased in NK T cells of BDL mice (fig 6B).

\section{Involvement of FasL, NK T cells, and TLR2 in liver injury after BDL}

BDL causes early hepatocellular injury. ${ }^{35}{ }^{36}$ Peak ALT levels were observed on day 1 after BDL in C57BL/6 mice (fig 7A). To investigate the involvement of Fas/FasL and TLR2 on liver NKT cells in liver injury following BDL, we compared serum 

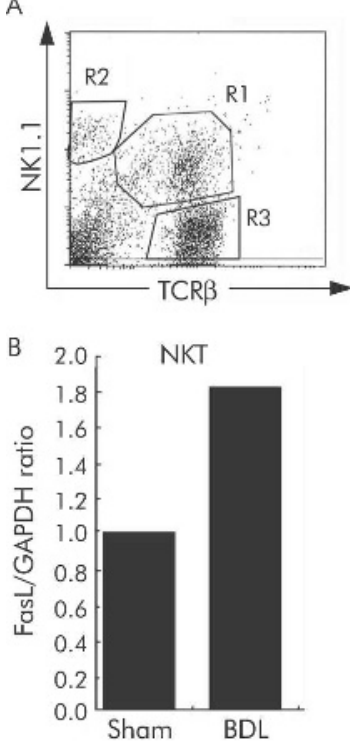

R1:NKT cells
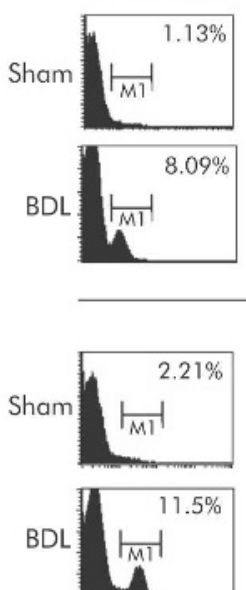

R2:NK cells

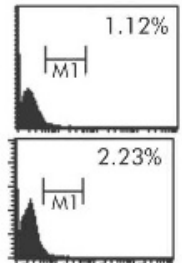

FasL
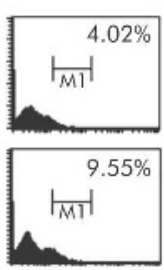

TLR2

Figure 6 Expression of Fas ligand (FasL) and Toll-like receptor 2 (TLR2) on intrahepatic lymphocytes of bile duct ligated (BDL) mice. Intrahepatic lymphocytes were isolated from the livers of $\mathrm{BDL}$ and sham operated mice on day 1 after BDL. Cells were collected and stained with anti-T cell receptor $\beta$ (TCR $\beta$ ), anti-NK1.1, and anti-FasL monoclonal antibodies (mAbs) or antiTLR2 mAb and analysed with a flow cytometer. Analysis gates were set on lymphocytes using forward and side scatter and on NKT, NK, or T cells. Data shown are representative of three separate experiments. (B) FasL gene expression in NKT cells sorted from liver on day 1 after BDL. mRNA was reverse transcribed into CDNA and quantitated with real time polymerase chain reaction. Expression was normalised as a ratio using rodent glyceraldehyde-3phosphate dehydrogenase (GAPDH) as a housekeeping RNA. A value of one for this ratio was arbitrarily assigned to the data of timed from sham operated mice.

ALT levels in V $\alpha 14$ NKT cell deficient $\left(\mathrm{J}_{2} 28 \mathrm{1}^{-/-}\right), \mathrm{lpr} / \mathrm{lpr}$, gld/ gld, TLR2 ${ }^{-/-}, \mathrm{MyD}^{-1-}, \mathrm{C} 57 \mathrm{BL} / 6, \mathrm{C} 3 \mathrm{H} / \mathrm{HeJ}$, and $\mathrm{C} 3 \mathrm{H} / \mathrm{HeN}$ mice after BDL. Serum ALT levels in $\mathrm{J} \alpha 28 \mathrm{1}^{-/-}$, gld/gld, and $\mathrm{TLR}^{-1-}$ mice were significantly lower than those in control C57BL/6 mice on day 1 after BDL (fig 7B). On the other hand, there was no difference in ALT levels between TLR4 mutated $\mathrm{C} 3 \mathrm{H} / \mathrm{HeJ}$ and control $\mathrm{C} 3 \mathrm{H} / \mathrm{HeN}$ mice after BDL (fig 7B). Differences in serum ALT serum among J $228 \mathrm{1}^{-/-}$, gld/gld, and $\mathrm{TLR}^{-/-}$mice and control C57BL/6 mice could not be attributed to differences in the magnitude of cholestasis because bilirubin levels were almost the same in these groups ( 13.5 (5.6) mg/dl for $\mathrm{J} \alpha 28 \mathrm{l}^{-1-}$ mice, 12.5 (3.6) $\mathrm{mg} / \mathrm{dl}$ for gld/ gld mice, 14.5 (3.9) mg/dl for $\mathrm{TLR}^{-/-}$mice, and 13.2 (4.6) $\mathrm{mg} / \mathrm{dl}$ for C57BL/6 mice).

Histopathological examination with haematoxylin-eosin staining of liver specimens on day 1 after BDL demonstrated bile duct proliferation, portal oedema, and mild portal infiltrates, indicating similar ductular responses of the liver to large bile duct obstruction in all groups. However, necroinflammatory foci, cell death of hepatocytes characterised by cell shrinkage and chromatin condensation, and lymphocyte infiltration were obviously less in $\mathrm{J} \alpha 281^{-/-}$, lpr, gld, $\mathrm{TLR}^{-/-}$, and $\mathrm{C} 3 \mathrm{H} / \mathrm{HeJ}$ mice than in control wild-type mice after BDL (fig 8A, B). Confluent foci of hepatocyte feathery degeneration due to bile acid cytotoxicity (bile infarcts) were significantly reduced in $\mathrm{J} \alpha 281^{-/-}(6.7$ (5.7) foci per low power field), $\operatorname{lp} / \operatorname{lpr}$ (9.3 (3.1) foci), gl/gld (12.5 (3.5) foci), and TLR2 ${ }^{-/-}$mice (8.3 (4.2) foci) compared with control mice (19.3 (4.2) foci) 24 hours after BDL $(p<0.05)$. To confirm the difference in frequency of apoptotic cells among these mutant mice, we identified apoptotic cells using the TUNEL technique and the numbers of TUNEL positive cells per field were quantified (fig 8C). Greater numbers of cells undergoing apoptosis were observed in the livers of control and $\mathrm{C} 3 \mathrm{H} / \mathrm{HeJ}$ mice whereas the numbers of apoptotic cells in $\mathrm{J} \alpha 281^{-/-}, \mathrm{lp} / \mathrm{lpr}, \mathrm{gl} / \mathrm{gld}, \mathrm{TLR} 2^{-/-}$, and
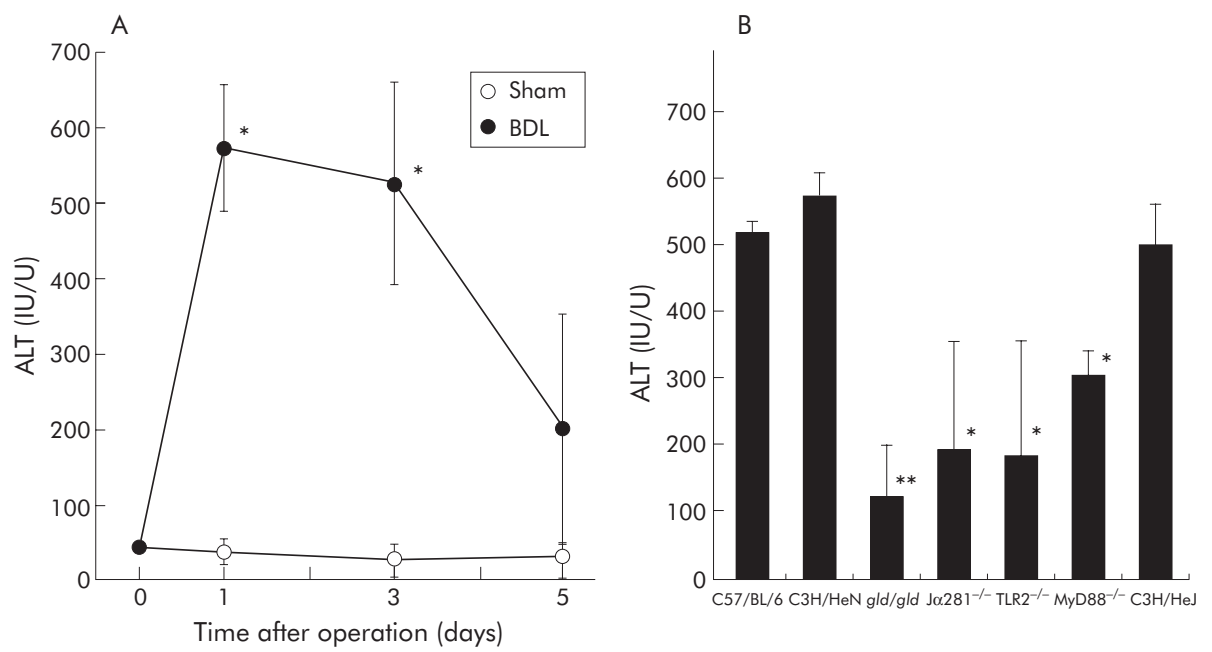

Figure 7 Liver injury in J $\alpha 281^{-/-}$, lpr/lpr, gld/gld, MyD88 $-1-$, TLR2 ${ }^{-/-}, \mathrm{C} 57 \mathrm{BL} / 6, \mathrm{C} 3 \mathrm{H} / \mathrm{HeN}$, and C3H/HeJ mice after bile duct ligation (BDL). (A) Kinetics of serum alanine aminotransferase (ALT) in C57BL/6 mice after BDL. Sera were collected at the indicated times after BDL in C57BL/6 mice and ALT levels in sera were measured. (B) Serum ALT on day 1 after BDL. Sera were collected 24 hours after BDL in $/ \mathrm{pr} / \mathrm{lpr}, \mathrm{gld} / \mathrm{gld}, \mathrm{J} \alpha 281^{-/-}$,

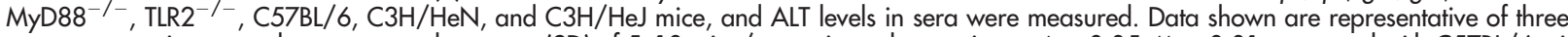
separate experiments and are expressed as mean (SD) of 5-10 mice/group in each experiment. ${ }^{*} p<0.05,{ }^{* *} p<0.01$ compared with C57BL/6 mice. 
A
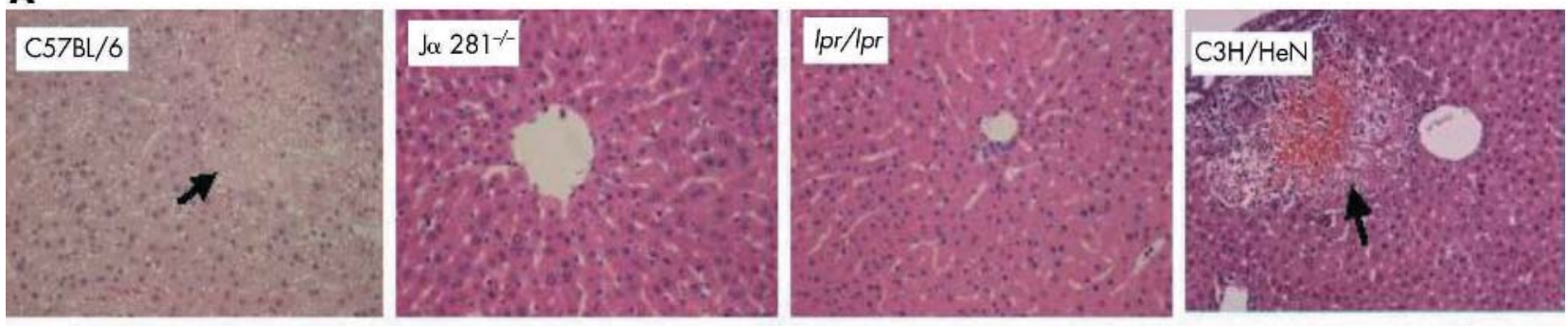

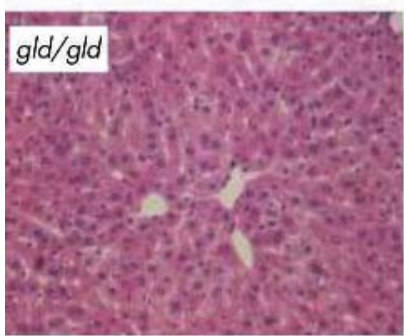

B

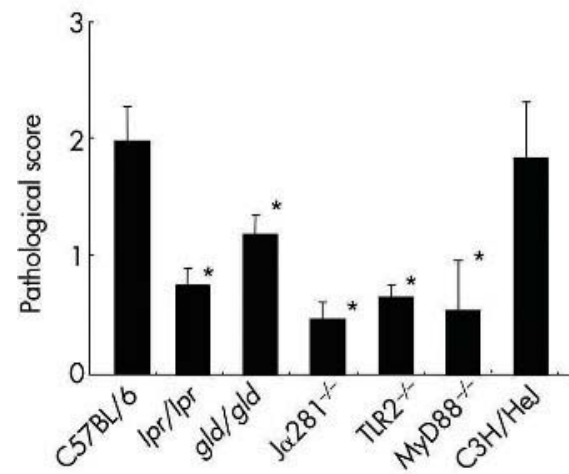

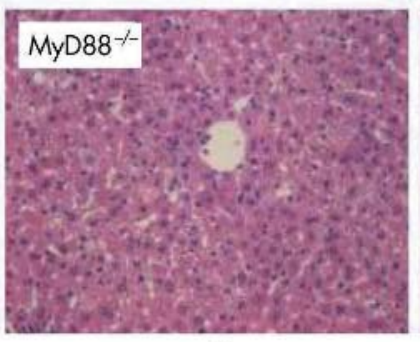

C

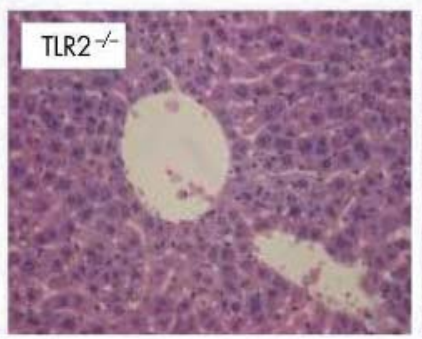

D
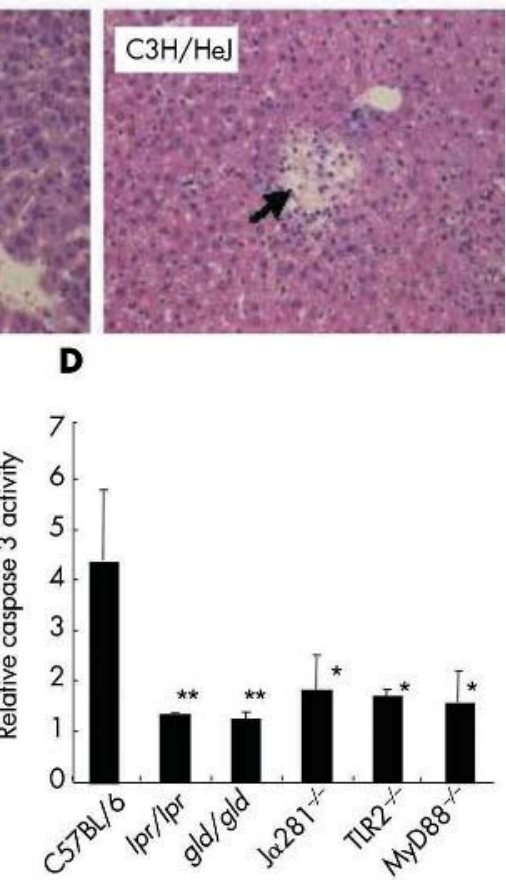

Figure 8 Apoptosis in the liver on day 1 after bile duct ligation (BDL). (A) Comparison of histological findings in liver specimens from J $\alpha 281^{-/-}$, Ipr/ lpr, gld/gld, MyD88 ${ }^{-1-}, \mathrm{TLR}^{-1-}, \mathrm{C} 57 \mathrm{BL} / 6, \mathrm{C} 3 \mathrm{H} / \mathrm{HeN}$, and $\mathrm{C} 3 \mathrm{H} / \mathrm{HeJ}$ mice 24 hours after BDL. Formalin fixed paraffin embedded thin specimens were stained with haematoxylin-eosin, and microscopic analyses were performed. Necroinflammatory foci are indicated by arrows. (B) Histological score in liver specimens from J $\alpha 281^{-1}$, lpr/lpr, gld/gld, MyD88 ${ }^{-/}$, TLR2 ${ }^{-1-}, \mathrm{C} 57 \mathrm{BL} / 6, \mathrm{C} 3 \mathrm{H} / \mathrm{HeN}$, and C3H/HeJ mice 24 hours after BDL. Liver sections were graded by a pathologist in a blinded fashion. Data shown are representative of three separate experiments and are expressed as mean (SD) of 5-10 mice/group in each experiment. * $\mathrm{p}<0.05$ compared with control mice. (C) Numbers of terminal deoxynucleotidyl transferase dUTP nick end labelling (TUNEL) positive cells per field in the liver of BDL mice. TUNEL staining revealed increased numbers of apoptotic cells in the livers of control mice compared with numbers in the livers of $/ p r / l p r, g l d / g l d, ~ J \alpha 281^{-/-}$, TLR2 ${ }^{-/-}$, and MyD88 ${ }^{-/-}$mice. Data shown are representative of three independent experiments and are expressed as mean (SD) of 5-10 mice/group in each experiment. * $p<0.05,{ }^{* *} p<0.01$ compared with control mice. (D) Caspase 3 activity in liver cell extracts on day 1 after BDL. Caspase 3 activity in liver cell extracts was measured with the Fluorometric CaspACE Assay System (Promega, Madison, Wisconsin, USA) at an excitation wavelength of $360 \mathrm{~nm}$ and an emission wavelength of $460 \mathrm{~nm}$. Data shown are representative of three independent experiments and are expressed as the mean (SD) of 5-10 mice/group in each experiment. ${ }^{*}<0.05$, ${ }^{* *} \mathrm{p}<0.01$ compared with control mice.

MyD88 ${ }^{-/-}$mice remained at smaller levels $(\mathrm{p}<0.05$ ) (fig $8 \mathrm{C}$ ). To further compare the degree of apoptosis in the liver of these mutant mice subjected to BDL, we examined the activities of caspase 3, a downstream caspase in apoptosis, in liver tissues on postoperative day 1 . Consistent with serum ATL levels and TUNEL positive cells, caspase 3 activity in $\mathrm{J} \alpha 281^{-/-}$, lpr/lpr, gld/gld, TLR2 ${ }^{-1-}$, and $\mathrm{MyD} 88^{-/-}$mice was significantly lower than that in control mice on day 1 after BDL $(p<0.05)$ (fig $8 \mathrm{D})$. Taken together, these results indicate that FasL, NKT cells, and TLR2 contribute to liver injury in the early stage after BDL

\section{DISCUSSION}

We have shown that increased apoptosis in Peyer's patch B cells is evident on day 1 after BDL in normal mice but not in

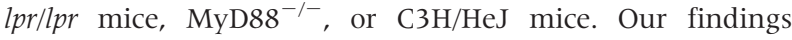
suggest that signalling from both Fas and TLR4 are involved in Peyer's patch B cell apoptosis after BDL. Although Fas is expressed only weakly on naive B cells, it is strongly expressed in B cells after antigen stimulation and is involved in negative selection in the germinal centre. ${ }^{43}{ }^{44}$ Fas expression is also upregulated by various stimuli such as stimulation by CD40. ${ }^{45}{ }^{46}$ We found that expression levels of Fas on Peyer's patch B cells were upregulated at the early stage after BDL, and the increase in apoptosis in Peyer's patch B cells appears to be an example of activation induced apoptosis of lymphocytes. We speculate that upregulation of Fas expression on $\mathrm{B}$ cells is in part a response to altered exposure to enteric antigens released due to increased gut permeability and microflora explosion observed during cholestasis. The production of IgA is a result of activation of Peyer's patch B cells. $^{24}$

We found that faecal IgA levels transiently increased very early after BDL, suggesting early activation of Peyer's patch $\mathrm{B}$ cells after BDL. Ayala et al recently reported that Fas was involved in Peyer's patch B cell apoptosis during 
polymicrobial sepsis caused by caecal ligation and puncture (CLP) and that the increase in apoptosis of Peyer's patch cells was coincident with an augmented endogenous IgA secretory response after CLP. ${ }^{47}$ Consistent with this finding, increased IgA production at the very early stage after BDL appears to be associated with an increase in activation induced apoptosis of Peyer's patch B cells via the Fas dependent pathway. On the other hand, they showed that TLR4 mediated process was not involved in increased B cell apoptosis during sepsis caused by CLP, ${ }^{48}$ which is inconsistent with our present results in obstructive cholestasis. It remains to be determined how TLR4 signalling is involved in Fas dependent apoptosis in B cells in obstructive cholestasis.

Toxic bile salts such as glycoenodeoxylase (GCDC) have been reported to increase the sensitivity of Fas mediated apoptosis. ${ }^{35}$ Therefore, bile acids in synergy with TLR4 ligands may induce efficient apoptosis in Peyer's patch B cells after BDL through elevation of Fas expression and/or increase in sensitivity to Fas mediated apoptosis.

Another notable finding in the present study is that TLR2, FasL, and NKT cells are responsible for the pathogenesis of liver injury at the early stage after BDL in mice. We have recently found that freshly isolated NK T cells from livers of naive mice expressed relatively high levels of TLR2 mRNA $^{17}$ and that freshly isolated NKT cells respond to synthetic lipoprotein, a ligand for TLR2, by inducing FasL on their surfaces, ${ }^{18}$ suggesting that TLR2 on NK T cells can be expressed on their surfaces and function to induce FasL expression on NK T cells. In the present study, we found that expression levels of TLR2 on NKT cells significantly increased after BDL. We have recently reported that TLR2 expressed by NK T cells in the liver contribute to liver injury induced by Gram negative bacteria such as $E$ coli and Salmonella choleraesuis in a FasL/Fas dependent manner. ${ }^{17}{ }^{18}$ Increased gut permeability and microflora explosion may be evident prior to bacterial translocation after BDL. It is possible that enteric antigens could be released from the gut to the liver in the early stage after BDL. Enteric bacterial stimulation in BDL mice may stimulate liver NKT cells via TLR2 to express FasL, aggravating liver injury at the early stage after BDL.

Miyoshi et al have recently reported that hepatocyte apoptosis after BDL in the mouse involves Fas. ${ }^{36}$ It has also been reported that bile acid induces hepatocyte apoptosis in the short term in vitro by a Fas dependent mechanism. Although $\mathrm{T}$ cells are a documented source of FasL and indispensable for Fas dependent apoptosis of various types of cells, ${ }^{49}{ }^{50}$ Faubion et al suggested that apoptosis induced by toxic bile salts such as GCDC involves ligand independent oligomerisation of Fas, recruitment of FADD, activation of caspase 8 , and subsequent activation of effector proteases, including downstream caspases by FasL independent mechanisms. ${ }^{35}$ However, $\mathrm{J} \alpha 281^{-/-}$mice deficient in NKT cells and gld/gld mice with mutated FasL showed significantly reduced levels of liver injury after BDL. We speculate a totally different mechanism of killing hepatocytes from their assumption that FasL on NKT cells stimulates Fas on hepatocytes to induce apoptosis after BDL.

In conclusion, TLR4 and TLR2 are important for Peyer's patch B cell apoptosis and NK T cell mediated liver injury, respectively, in a Fas dependent pathway. Our results should be useful for the development of a prophylactic approach to control pathogenesis associated with obstructive cholestasis.

\section{ACKNOWLEDGEMENTS}

This work was partly supported by a Grant-in Aid for Scientific Research on Priority Areas by the Japan Society for the Promotion of Science, Yakult Bioscience Foundation, and Uehara Memorial Foundation. We thank Miss Kaneda and Miss Kobayashi for their technical assistance.

\section{Authors' affiliations}

A Ogawa, T Tagawa, H Nishimura, T Yajima, Y Yoshikai, Division of Host Defense, Research Centre of Prevention of Infectious Diseases, Medical Institute of Bioregulation, Kyushu University, Fukuoka, Japan T Abe, T Arai, Y Nimura, Division of Surgical Oncology, Department of Surgery, Nagoya University Graduate School of Medicine, Nagoya, Japan

M Taniguchi, Laboratory for Immune Regulation, RIKEN Research Centre for Allergy and Immunology, and Department of Molecular Immunology, Graduate School of Medicine, Chiba University, Chiba, Japan

K Takeda, Division of Embryonic and Genetic Engineering, Medical Institute of Bioregulation, Kyushu University, Fukuoka, Japan

S Akira, Department of Host Defense, Research Institute for Microbial Diseases, Osaka University, Osaka, Japan

Conflict of interest: None declared.

\section{REFERENCES}

1 Hashimoto C, Hudson KL, Anderson KV. The Toll gene of Drosophia, required for dorsal-ventral embryonic polarity appears to encode a transmembrane protein. Cell 1988;52:269-79.

2 Lemaitre B, Nicolas E, Michaut L, et al. The dorsoventral regulatory gene cassette spatzle/Toll/cactus controls the potent antifungal response in Drosophila adults. Cell 1996;86:973-83.

3 Hoffmann JA, Kafatos FC, Janeway CA Jr, et al. Phylogenetic perspectives in innate immunity. Science 1999;284:1313-18.

4 Takeda K, Kaisho T, Akira S. Toll-like receptors. Annu Rev Immunol 2003:21:335-76.

5 Lien E, Sellati TJ, Yoshimura A, et al. Toll-like receptor 2 functions as a patternrecognition receptor for diverse bacterial products. J Biol Chem $1999 ; 274: 33419-25$.

6 Takeuchi O, Hoshino K, Kawai T, et al. Differential roles of TLR2 and TLR4 in recognition of gram-negative and gram-positive bacterial cell wall components. Immunity 1999;1 1:443-51.

7 Ozinsky A, Underhill DM, Fontenot JD, et al. The repertoire for pattern recognition of pathogens by the innate immune system is defined by cooperation between toll-like receptors. Proc Natl Acad Sci U S A 2000;97:13766-71

8 Poltorak A, He X, Smirnova I, et al. Defective LPS signaling in $\mathrm{C} 3 \mathrm{H} / \mathrm{HeJ}$ and C57BL/10ScCr mice: mutations in the tru gene. Science 1998;282:2085-8.

9 Brightbill HD, Libraty DH, Krutzik SR, et al. Host defense mechanisms triggered by microbial lipoproteins through Toll-like receptors. Science 1999;285:732-6.

10 Hemmi H, Takeuchi O, Kawai T, et al. A Toll-like receptor recognizes bacterial DNA. Nature 2000;408:740-5.

11 Hayashi F, Smith KD, Ozinsky A, et al. The innate immune response to bacterial flagellin is mediated by Toll-like receptor 5. Nature 2001;410:1099-103

12 Lena A, Agnieszka CH, Ruslan $M$, et al. Recognition of double-stranded RNA and activation of NF-B by Toll-like receptor 3. Nature 2001;413:732-8.

13 Hemmi H, Kaisho T, Takeuchi O, et al. Small anti-viral compounds activate immune cells via the TLR7 MyD88-dependent signaling pathway. Nat Immunol 2002;3:196-200.

14 Lolis E, Bucala R. Therapeutic approaches to innate immunity: severe sepsis and septic shock. Nat Rev Drug Discov 2003;2:635-45.

15 Sato S, Takeuchi O, Fujita T, et al. A variety of microbial components induce tolerance to lipopolysaccharide by differentially affecting MyD88-dependent and -independent pathways. Int Immunol 2002; 14:783-91.

16 Mokuno Y, Matsuguchi T, Takano M, et al. Expression of Toll-like receptor 2 on $\gamma \delta \mathrm{T}$ cells bearing invariant $\mathrm{V} \gamma 6 / \mathrm{V} \delta 1$ indyced by Escherichia coli infection. J Immunol 2000;165:931-40.

17 Shimizu H, Matsuguchi T, Fukuda Y, et al. Toll-like receptor 2 contributes to liver injury induced by Salmonella infection through Fas ligand expression on NKT cells in mice. Gastroenterology 2002;123:1265-77.

18 Hiromatsu T, Matsuguchi T, Shimizu H, et al. NK T cells stimulated with a ligand for TLR2 contribute to liver injury caused by Escherichia coli infection in mice. Eur J Immunol 2003;33:251 1-19.

19 Scott-Conner CE, Grogan JB. The pathophysiology of biliary obstruction and its effect on phagocytic and immune function. J Surg Res 1994;57:316-36.

20 Dixon JM, Armstrong CP, Duffy SW, et al. Factors affecting morbidity and mortality after surgery for obstructive jaundice: a review of 373 patients. Gut 1983;24:845-52.

21 Trauner M, Meier PJ, Boyer JL. Molecular pathogenesis of cholestasis. N Engl J Med 1998;339:1217-27.

22 Deitch EA, Sittig K, Li M, et al. Obstructive jaundice promotes bacterial translocation from the gut. Am J Surg 1990; 159:79-84.

23 Slocum MM, Sittig KM, Specian RD, et al. Absence of intestinal bile promotes bacterial translocation. Am Surg 1992;58:305-10.

24 Clements WD, Parks R, Erwin P, et al. Role of the gut in the pathophysiology of extrahepatic biliary obstruction. Gut 1996;39:587-93.

25 Sheen-Chen SM, Chau P, Harris HW. Obstructive jaundice alters Kupffer cell function independent of bacterial translocation. J Surg Res 1998;80:205-9.

26 Arai T, Yoshikai Y, Kamiya J, et al. Bilirubin impairs bactericidal activity of neutrophils through an antioxidant mechanism in vitro. J Surg Res 2001;96:107-13. 
27 Yamamoto S, Kubota Y, Tsuji K, et al. Effect of obstructive jaundice on neutrophil chemotactic activity: an in vivo assessment in zymosan-induced peritonitis model in rats. J Gastroenterol Hepatol 1998;13:405-11.

28 Tjandra K, Woodman RC, Swain MG. Impaired neutrophil microbicidal activity in rat cholestasis. Gastroenterology 1997;112:1692-8.

29 Schmucker DL, Ohta M, Kanai S, et al. Hepatic injury induced by bile salts: correlation between biochemical and morphological events. Hepatology 1990;12:1216-21.

30 Patel T, Bronk SF, Gores GJ. Increases of intracellular magnesium promote glycodeoxycholate-induced apoptosis in rat hepatocytes. J Clin Invest 1994;94:2183-92.

31 Benz C, Angermuller S, Tox U, et al. Effect of tauroursodeoxycholic acid on bile-acid-induced apoptosis and cytolysis in rat hepatocytes. J Hepatol 1998;28:99-106.

32 Rodrigues CM, Fan G, Wong PY, et al. Ursodeoxycholic acid may inhibit deoxycholic acid-induced apoptosis by modulating mitochondrial transmembrane potential and reactive oxygen species production. Mol Med 1998;4:165-78.

33 Rodrigues CMP, Fan G, Xiaoming M, et al. A novel role for ursodeoxycholic acid in inhibiting apoptosis by modulating mitochondrial membrane perturbation. J Clin Invest 1998;101:2790-9.

34 Webster CR, Anwer MS. Cyclic adenosine monophosphate-mediated protection against bile acid-induced apoptosis in cultured rat hepatocytes. Hepatology 1998;27:1324-31.

35 Faubion WA, Guicciardi ME, Miyoshi $\mathrm{H}$, et al. Toxic bile salts induce rodent hepatocyte apoptosis via direct activation of Fas. J Clin Invest 1999; 103:137-45.

36 Miyoshi H, Rust C, Roberts PJ, et al. Hepatocyte apoptosis after bile duct ligation in the mouse involves Fas. Gastroenterology 1999;117:669-77.

37 Canbay A, Higuchi H, Bronk SF, et al. Fas enhances fibrogenesis in the bile duct ligated mouse: a link between apoptosis and fibrosis. Gastroenterology $2002 ; 123: 1323-30$
38 Cui J, Shin T, Kawano T, et al Requirement for Valphal 4 NKT cells in IL-12mediated rejection of tumors. Science 1997;285:732-6.

39 Fagarasan S, Honjo T. Intestinal IgA synthesis: regulation of front-line body defences. Nat Rev Immunol 2003:3:63-72.

40 Wang J, Watanabe T. Expression and function of Fas during differentiation and activation of B cells. Int Rev Immunol 1999;18:367-79.

41 Kehry MR. CD40-mediated signaling in B cells. Balancing cell survival, growth, and death. J Immunol 1996;156:2345-8.

42 Carey GB, Donjerkovic D, Mueller CM, et al. B-cell receptor and Fas-mediated signals for life and death. Immunol Rev 2000;176:105-15.

43 Onel KB, Tucek-Szabo CL, Ashany D, et al. Expression and function of the murine CD95/FasR/APO-1 receptor in relation to $B$ cell ontogeny. Eur J Immunol 1995;25:2940-7.

44 Mandik L, Nguyen KA, Erikson J. Fas receptor expression on B-lineage cells. Eur J Immunol 1995;25:3148-54.

45 Watanabe D, Suda T, Nagata S. Expression of Fas in B cells of the mouse germinal center and Fas-dependent killing of activated B cells. Int Immunol 1995; 7:1949-56

46 Fukuyama $\mathrm{H}$, Adachi $M$, Suematsu $S$, et al. Requirement of Fas expression in $B$ cells for tolerance induction. Eur J Immunol 2002:32:223-30.

47 Ayala A, Xin Xu Y, Ayala CA, et al. Increased mucosal B-lymphocyte apoptosis during polymicrobial sepsis is a Fas ligand but not an endotoxinmediated process. Blood 1998:91:1362-72.

48 Chung CS, Wang W, Chaudry $\mathrm{IH}$, et al. Increased apoptosis in lamina propria $B$ cells during polymicrobial sepsis is Fas L but not endotoxin mediated. Am J Physiol Gastrointest Liver Physiol 2001;280:812-18.

49 Tibbetts MD, Zheng L, Lenardo MJ. The death effector domain protein family: regulators of cellular homeostasis. Nat Immunol 2003:4:404-9.

50 Thome M, Tschopp J. Regulation of lymphocyte proliferation and death by FLIP. Nat Rev Immunol 2001;1:50-8.

\section{EDITOR'S QUIZ: GI SNAPSHOT}

\begin{abstract}
Answer
From question on page 104

The endoscopy image (fig 1) demonstrates florid duodenal varices. Figure 2 shows an atrophic calcified pancreas in keeping with a history of acute pancreatitis complicated by pseudocyst formation and subsequent chronic pancreatitis. Figure 3 illustrates splenic vein thrombosis at the splenic hilum along with extensive duodenal varices. Surprisingly, gastric varices were not demonstrated. The patient continued to be transfusion dependent and haemodynamically unstable and was transferred to the regional liver unit for a splenectomy. He remains well at follow up.

Splenic vein thrombosis complicates acute pancreatitis in up to $19 \%$ of cases. ${ }^{1}$ Other causes include pancreatic adenocarcinoma, pancreatic cysts, or pseudocysts. Rarely it may also be caused by hypercoaguable states, including nephrotic syndrome and sickle cell anaemia. Pathophysiologically, splenic blood is shunted into the portal circulation through the short gastric vessels, resulting in the formation of gastric and duodenal varices. Oesophageal varices are uncommon in this situation because the collateral circulation does not involve the oesophagus. Variceal bleeding occurs in only $4 \%$ of patients with splenic vein thrombosis and treatment consists of either a splenectomy or splenic artery embolisation. ${ }^{2}$ Patient outcome depends on the aetiology of the splenic vein thrombosis.
\end{abstract}

doi: 10.1136/gut.2005.070037

\section{REFERENCES}

1 Mortele KJ, et al. Splenic and perisplenic involvement in acute pancreatitis: determination of prevalence and morphological helical CT features. J Comput Assist Tomogr 2001;25:50-4.

2 Heider TR, et al. The natural history of pancreatitis-induced splenic vein thrombosis. Ann Surg 2004;239:876-80. 